\begin{tabular}{|c|c|c|}
\hline \multirow{3}{*}{$\begin{array}{r}\text { Case Reports in } \\
\text { Gastroenterology }\end{array}$} & \multirow{2}{*}{\multicolumn{2}{|c|}{ Case Rep Gastroenterol 2014;8:291-296 }} \\
\hline & & \\
\hline & $\begin{array}{l}\text { DOI: 10.1159/000368303 } \\
\text { Published onine: October 7, } 2014\end{array}$ & $\begin{array}{l}\text { ○ } 2014 \text { S. Karger AG, Basel } \\
\text { 1662-0631/14/0083-0291 } \$ 39.50 / 0 \\
\text { www.karger.com/crg }\end{array}$ \\
\hline & \multicolumn{2}{|c|}{$\begin{array}{l}\text { This is an Open Access article licensed under the terms of the Creative Commons } \\
\text { Attribution-NonCommercial } 3.0 \text { Unported license (CC BY-NC) (www.karger.com/OA } \\
\text { license), applicable to the online version of the article only. Distribution permitted for non } \\
\text { commercial purposes only. }\end{array}$} \\
\hline
\end{tabular}
commercial purposes only.

\title{
Accessory Pancreatic Duct-Portal Vein Fistula: A Rare Complication of Chronic Pancreatitis during Endoscopic Retrograde Cholangiopancreatography
}

\author{
Yoshiaki Kawaguchi Jung-Chun Lin Yohei Kawashima Atsuko Maruno \\ Hiroyuki Ito Masami Ogawa Tetsuya Mine \\ Department of Gastroenterology, Tokai University School of Medicine, Isehara, Japan
}

\section{Key Words}

Accessory pancreatic duct-portal vein fistula · Chronic pancreatitis - Endoscopic retrograde cholangiopancreatography

\begin{abstract}
Pancreatitis, hemorrhage and perforation are the most frequent complications associated with endoscopic retrograde cholangiopancreatography (ERCP). We report a rare case of accessory pancreatic duct-portal vein fistula, which occurred during ERCP in a patient with chronic pancreatitis. To our knowledge, this is the first report of accessory pancreatic ductportal vein fistula created during ERCP by the use of a guide wire.

(C) 2014 S. Karger AG, Basel
\end{abstract}

\section{Introduction}

Endoscopic retrograde cholangiopancreatography (ERCP) has become widely available for the diagnosis and treatment of benign and malignant pancreaticobiliary diseases. However, it is important to understand the potential complications and risks of diagnostic and therapeutic ERCP. Acute pancreatitis, duodenal perforation, hemorrhage, and cholangitis are well-known complications. Other complications are unusual. A recent study reported 327 (11.6\%) complications in 2,808 ERCP procedures, of which 2,573 (91.6\%) were therapeutic; these 327 complications included cholangitis in 100 (3.6\%) cases, pancreatitis in $88(3.1 \%)$, bleeding in $66(2.4 \%)$, perforation in $25(0.9 \%)$, and cardiovascular-respiratory events in 32 
Kawaguchi et al.: Accessory Pancreatic Duct-Portal Vein Fistula: A Rare Complication of Chronic Pancreatitis during Endoscopic Retrograde Cholangiopancreatography

(1.1\%) [1]. Acute pancreatitis is a serious complication of ERCP. The frequency of post-ERCP pancreatitis varies between 1 and 9\% [2] in average-risk patients.

We experienced iatrogenic portobiliary fistula, which is a very uncommon complication of ERCP. This complication may result in bleeding, sepsis, portal thrombosis, and air embolism $[3,4]$. We have decided to share this finding because this rare complication should be regarded as a potential complication when ERCP is performed in patients with malignant disease and chronic pancreatitis. It is important for endoscopists to recognize this complication immediately and that no further intervention is performed. A search of the literature was carried out to compare this case with others previously reported.

\section{Case Report}

Our patient was a 42-year-old man. He has received insulin treatment for diabetes since the age of 34. Before his diagnosis of diabetes, he had drunk in large quantities, and he has had a smoking history of 20 cigarettes per day for 15 years. His family history was unremarkable. Regarding the present illness, he visited a neighborhood clinic with a chief complaint of severe back pain. Abdominal CT revealed dilatation of the main pancreatic duct and pancreatic stones (fig. 1). Chronic pancreatitis was diagnosed, and the patient was referred to our hospital. Physical examination revealed no abnormal abdominal findings. Blood tests revealed no increase in amylase and hepatobiliary enzymes, the absence of jaundice, and no increase in inflammatory findings; however, his HbA1c level was high (7.8\%).

First, we performed extracorporeal shock wave lithotripsy (ESWL). After several daily 1-hour ESWL sessions, ERCP was performed via the main pancreatic duct. However, deep cannulation attempts into the pancreatic duct failed because of pancreatic stenosis (fig. 2). Next, we tried to achieve deep cannulation via the accessory pancreatic duct, but this was prevented by a stenotic lesion in the accessory pancreatic duct. We switched the procedure to the accessory pancreatic duct using a guide wire (fig. 3). Contrast medium was then injected through a catheter and was seen to flow quickly in the direction of the liver (fig. 4). We speculated that a fistula had developed between the posterior superior pancreatoduodenal vein and the accessory pancreatic duct, and so the procedure was terminated, and the catheter was withdrawn immediately. Duodenoscopy showed small amounts of blood from the minor papilla (fig. 5). The patient's subsequent progress was uneventful, and no clinical symptoms of hemorrhage developed. There was no clot in the portal vein. Up to now he has been followed up using analgesics without surgical intervention.

\section{Discussion}

Pancreatic duct-portal vein fistula is a very rare complication of ERCP. Visualization of a fistula of the portal venous system during ERCP has an incidence rate of about 1 in 6,0008,000 cases, occurring in patients with pancreatic carcinoma, cholelithiasis and chronic pancreatitis $[3,4]$. Such fistulas have also been observed with various cannulation techniques, including wire-guided cannulation, needle-knife sphincterotomy, and endoscopic nasobiliary drainage [5-9].

Repeated trial of wire-guided cannulation may also cause the guide wire to go into the branch pancreatic duct and the portal vein through the pancreas parenchyma. As a complication of ERCP, these fistulas can result from the laceration of a small portal vein or from a direct trauma to the papilla, and neo-angiogenesis or the aberrant development of 
Kawaguchi et al.: Accessory Pancreatic Duct-Portal Vein Fistula: A Rare Complication of Chronic Pancreatitis during Endoscopic Retrograde Cholangiopancreatography

blood vessels within the tissue resulting from cancer or infection can also explain their occurrence [8].

In this case, the patient underwent ESWL several times before ERCP. ESWL itself may cause pancreatic duct injury due to the trembling stones. Under these circumstances, aggressive guide wire insertion attempts might induce pancreatic duct-portal vein fistula. In addition, filling of the portal vein during ERCP can result in hemorrhage, sepsis, portal thrombosis, and air embolism [8], but aspiration of the duct before the injection of a contrast medium may facilitate prompt diagnosis. Though no serious complications have been reported, immediate withdrawal of the catheter does not cause any serious problems [9].

To avoid portal vein filling, ERCP must be performed more carefully in patients with pancreatic carcinoma or pancreatitis $[3,5,6,8]$. Also, we should pay additional attention when we perform ESWL for chronic pancreatitis. A rare, but possible, cause of the presence of portal vein filling is the direct passage of the guide wire/catheter from the pancreatic duct into the portal vein.

To our knowledge, this is the first report of accessory pancreatic duct-portal vein fistula created during ERCP by the use of a guide wire. More attention should be paid to the use of a guide wire during ERCP.

\section{References}

1 Glomsaker T, Hoff G, Kvaløy JT, et al: Patterns and predictive factors of complications after endoscopic retrograde cholangiopancreatography. Br J Surg 2013;100:373-380.

-2 Kawaguchi Y, Ogawa M, Omata F, et al: Randomized controlled trial of pancreatic stenting to prevent pancreatitis after endoscopic retrograde cholangiopancreatography. World J Gastroenterol 2012;18: 1635-1641.

-3 Ricci E, Mortilla MG, Conigliaro R, et al: Portal vein filling: a rare complication associated with ERCP for endoscopic biliary stent placement. Gastrointest Endosc 1992;38:524-525.

4 Siegel JH, Ben Zvi JS, Yatto RP: Portal vein filling during ERCP. Gastrointest Endosc 1993;39:471-472.

5 Huibregtse K, Gish R, Tytgat GN: A frightening event during endoscopic papillotomy. Gastrointest Endosc 1988;34:67-68.

6 Lum C, Cho KC, Scholl DG, et al: Portal vein opacification during ERCP in patients with pancreatitis. Abdom Imaging 1998;23:81-83.

7 Kawakami H, Kuwatani M, Kudo T, Ehira N, Yamato H, Asaka M: Portobiliary fistula: unusual complication of wire-guided cannulation during endoscopic retrograde cholangiopancreatography. Endoscopy 2011;43: E98-E99.

8 Espinel J, Pinedo ME, Calleja JL: Portal vein filling: an unusual complication of needle-knife sphincterotomy. Endoscopy 2007;39(suppl 1):E245.

-9 Furuzono M, Hirata N, Saitou J, et al: A rare complication during ERCP and sphincterotomy: placement of an endoscopic nasobiliary drainage tube in the portal vein. Gastrointest Endosc 2009;70:588-590. 
Kawaguchi et al.: Accessory Pancreatic Duct-Portal Vein Fistula: A Rare Complication of Chronic Pancreatitis during Endoscopic Retrograde Cholangiopancreatography

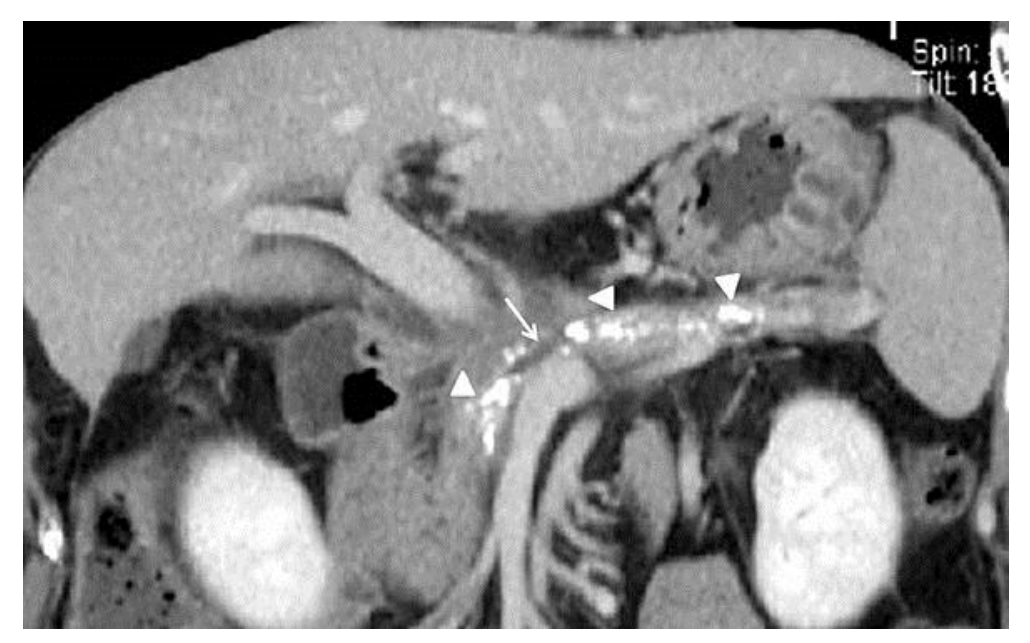

Fig. 1. Abdominal CT revealed dilatation of the main pancreatic duct (arrow) and pancreatic stones (arrowheads).

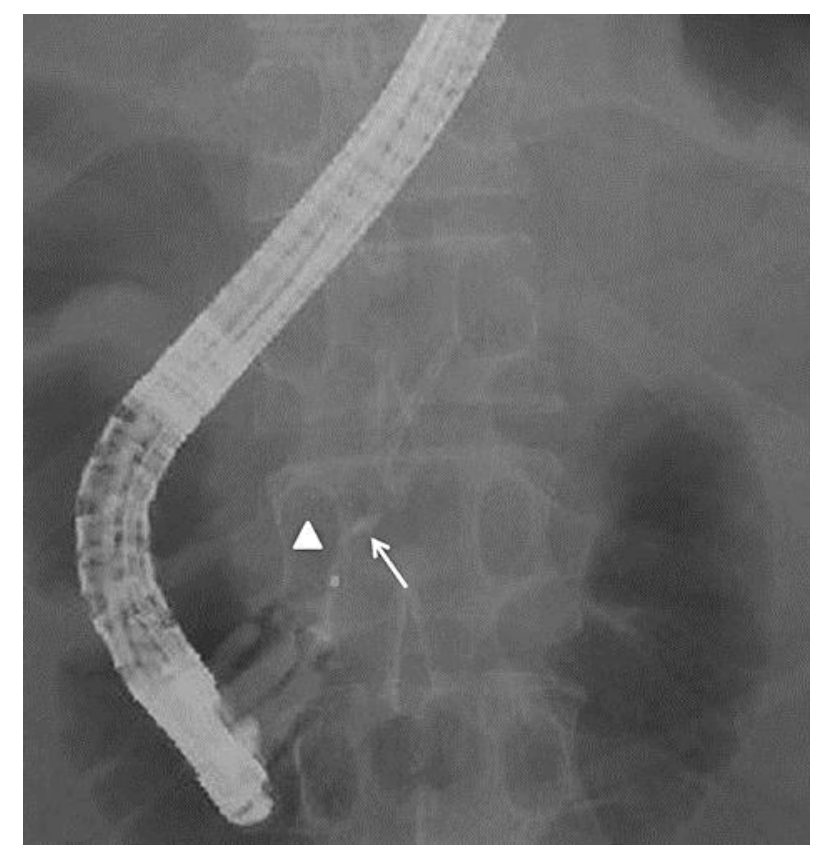

Fig. 2. ERCP revealed the main pancreatic duct (arrow). However, deep cannulation attempts into the pancreatic duct failed because of pancreatic stenosis (arrowhead). 


\section{Case Reports in \\ Gastroenterology}

\begin{tabular}{l|l}
\hline \multicolumn{2}{l}{ Case Rep Gastroenterol 2014;8:291-296 } \\
\hline DOI: 10.1159/000368303 & $\begin{array}{l}\text { ○ 2014 S. Karger AG, Basel } \\
\text { www.karger.com/crg }\end{array}$ \\
\hline
\end{tabular}

Kawaguchi et al.: Accessory Pancreatic Duct-Portal Vein Fistula: A Rare Complication of Chronic Pancreatitis during Endoscopic Retrograde Cholangiopancreatography

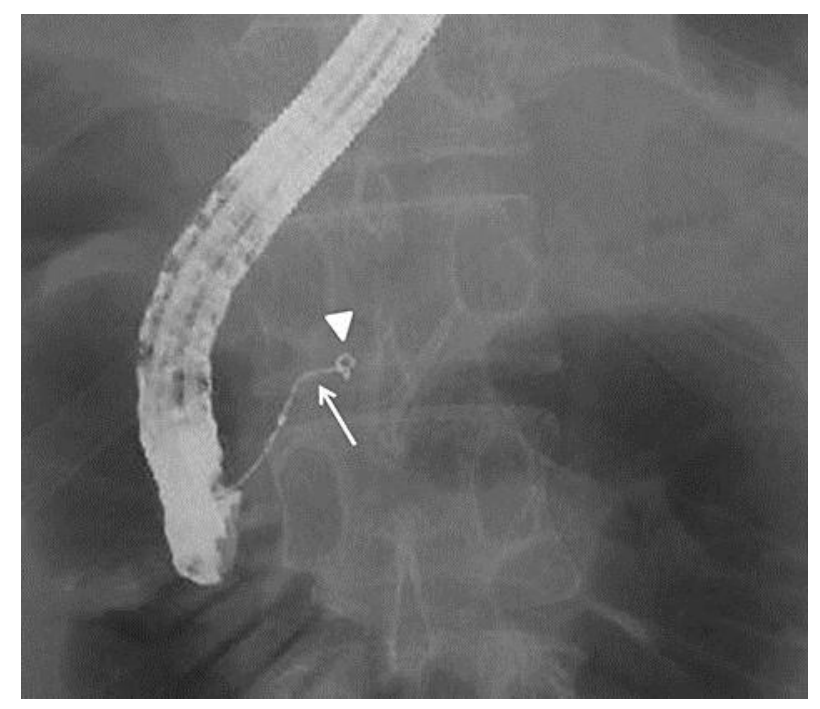

Fig. 3. ERCP revealed the accessory pancreatic duct, but deep cannulation was prevented by a stenotic lesion (arrowhead) in the accessory pancreatic duct. We switched the procedure to the accessory pancreatic duct using a guide wire (arrow).

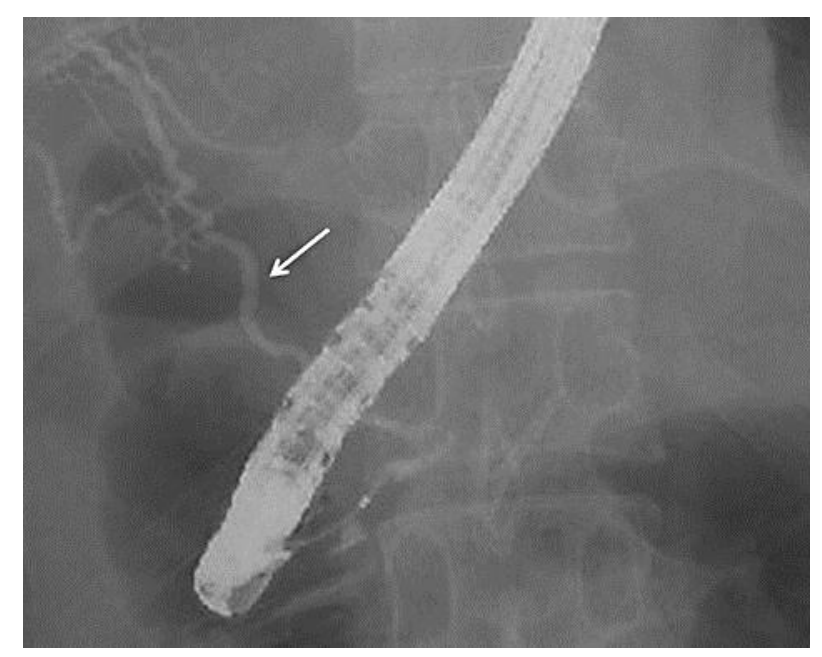

Fig. 4. Contrast medium was then injected through a catheter and was seen to flow quickly in the direction of the liver (arrow). 
Kawaguchi et al.: Accessory Pancreatic Duct-Portal Vein Fistula: A Rare Complication of Chronic Pancreatitis during Endoscopic Retrograde Cholangiopancreatography

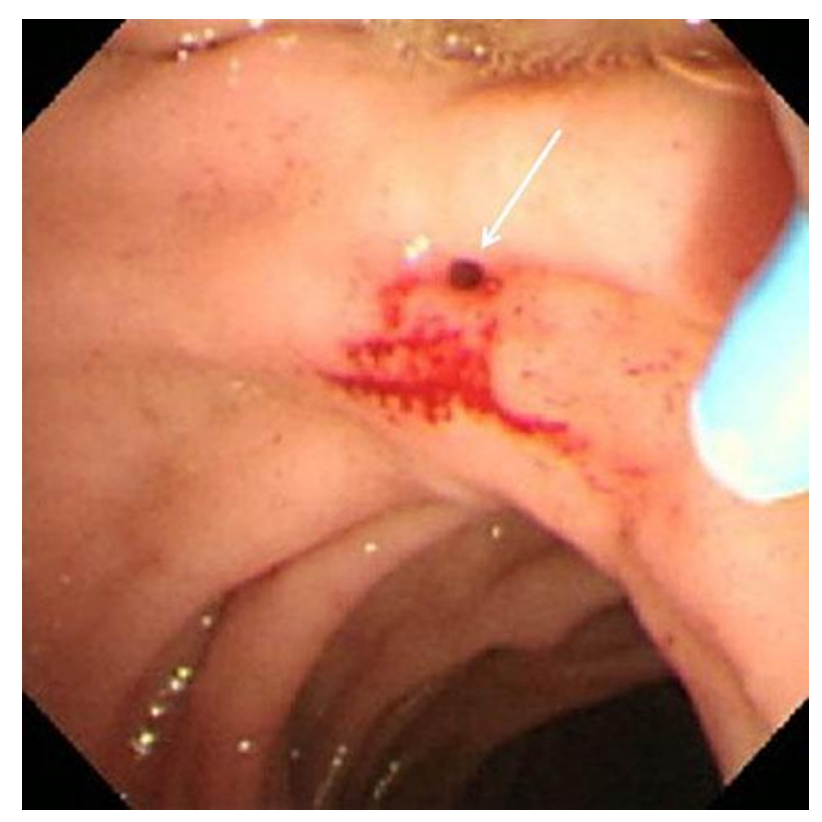

Fig. 5. Duodenoscopy showed small amounts of blood from the minor papilla (arrow). 